\title{
DIFERENÇA DE ESTATURA E DESIGUALDADE DE GÉNERO Que argumentário sociológico?
}

\author{
Michel Messu \\ Université Paris Descartes, Centre de Recherche PHILèPOL, Philosophie, Épistémologie \\ et Politique, Paris, França
}

Cristina Albuquerque

Universidade de Coimbra, Coimbra, Portugal

Resumo O presente artigo procura enfatizar a necessidade de, no âmbito da sociologia, distinguir os argumentos de explicação científica e os argumentos de explicação ideológica. Por via de um exemplo referente à diferença de estatura entre os dois sexos, são explicitadas e discutidas as incongruências epistemológicas da passagem de julgamentos de facto a julgamentos de valor. Estes exigiriam, desde logo, a clarificação dos pressupostos inerentes à respetiva enunciação. Neste sentido, procura-se argumentar que, ao mudar de quadro explicativo, se pode passar, sub-repticiamente, do registo factual ao registo valorativo, atribuindo, assim, a uma diferença de estatura o sentido de uma desigualdade de género.

Palavras-chave: epistemologia, sociologia, diferença de estatura, desigualdade de género.

Abstract The present article seeks to emphasize the need to distinguish, in sociology, the arguments of scientific explanation and the arguments of ideological explanation. Using an example associated with the difference in stature between the two sexes, the epistemological incongruities of passing from de facto judgments to value judgments - which would require a clarification of the assumptions inherent to their enunciation - are explained and discussed. In this sense, it is argued that, by changing the explanatory framework, one can, surreptitiously, move from the factual record to the valuation record, thus attributing to a difference of stature the meaning of a gender inequality.

Keywords: epistemology, sociology, difference in height, gender inequality.

Résumé Le présent article cherche à souligner la nécessité, dans le cadre de la sociologie, de distinguer les arguments d'explication scientifique des arguments d'explication idéologique. En utilisant comme exemple la différence de taille entre les deux sexes, sont explicitées et discutées les incongruités épistémologiques du passage des jugements de fait aux jugements de valeur. Ces derniers nécessiteraient une clarification des hypothèses sous-jacentes à leur énonciation. En ce sens, nous faisons valoir qu'en modifiant le cadre explicatif nous passons, subrepticement, du registre factuel au registre axiologique, attribuant ainsi à une différence de taille la signification d'une inégalité entre les sexes.

Mots-clés: épistémologie, sociologie, différence de taille, inégalité entre les sexes.

Resumen El presente artículo busca enfatizar la necesidad de, en el ámbito de la sociología, distinguir los argumentos de explicación científica y los argumentos de explicación ideológica. A través de un ejemplo asociado a la diferencia de estatura entre los dos sexos, se explicitan y discutieron las incongruencias epistemológicas de la transición del juicio de hecho al juicio de valor. Éste exigiría, desde luego, la clarificación de los supuestos inherentes a la respectiva enunciación. En este sentido, se pretende argumentar que, al cambiar de marco explicativo, se puede pasar del registro fáctico al registro valorativo, atribuyendo así a una diferencia de estatura el sentido de una desigualdad de género.

Palabras-clave: epistemología, sociología, diferencia de estatura, desigualdad de género. 


\section{Introdução}

A noção de desigualdade aplicada ao domínio social é, simultaneamente, uma das mais comummente utilizadas, mas também, uma das mais imprecisas e, até mesmo, ardilosa. Refira-se a este propósito, por exemplo, a relação que por vezes é estabelecida entre o conceito de desigualdade e uma dada conceção de justiça social. Esta relação, quase espontaneamente efetuada, conduz, por vezes, a importantes enviesamentos de raciocínio. No presente artigo procura-se discutir esta ideia, utilizando, para o efeito, um exemplo que poderia ser considerado trivial: o das diferenças de estatura entre homens e mulheres.

A reflexão sobre a conexão entre justiça e igualdade ganhou relevância sobretudo desde o século V antes da nossa era, na Grécia Antiga. Apesar de ter perdurado a inextricabilidade concetual entre as duas noções, a reflexão, então produzida, permitiu a precisão semântica da relação a estabelecer entre os dois conceitos e viria a consubstanciar as teorias da justiça que hoje conhecemos. Neste âmbito, ainda que Aristóteles e a sua Ética a Nicómaco tenham de ser referidos em primeiro plano, a compreensão das razões pelas quais seriam legitimadas "desigualdades justas" continuou a ser objeto de análise e discussão até aos nossos dias. Pode mesmo afirmar-se que, num plano macrossocial e ideológico, as "desigualdades justas" do passado podem transmutar-se, na atualidade, em injustiças inaceitáveis.

Neste âmbito, a teoria do género, pelo menos em tudo o que ela pode agregar, tem protagonizado debates relevantes e, ao mesmo tempo, controversos. Em muitas abordagens no domínio em epígrafe, a revelação da injustiça feita às mulheres dissimula-se sob a "desigualdade natural" que lhes é atribuída e/ou que elas mesmas se atribuiriam. Mesmo tornando-se ilegítima pelos discursos de contestação, pela ideologia dominante das sociedades democráticas e, talvez sobretudo, pelas transformações dos quadros legais, esta "natural desigualdade" continuou, ao longo do tempo, a ser invocada e a exigir revelação, desconstrução e supressão.

Seguindo este esquema explicativo, toda a desigualdade homem/mulher comportaria uma injustiça e, neste sentido, mereceria ser denunciada antes de ser corrigida. Mas será isto tão simples? Podemos passar automaticamente de uma desigualdade de distribuição para uma injustiça de condição? O salto qualitativo, a passagem do quantum à qualificação substantiva estaria, neste caso, autorizada?

Se se pretender responder afirmativamente a esta interrogação deve-se reconhecer que, pelo menos em certos casos, não o poderemos fazer sem recorrer a pressupostos teóricos que ultrapassam o quadro disciplinar da sociologia. Na verdade, a passagem de uma desigualdade de distribuição para uma injustiça de condição não se evidencia per se, mas apela a saberes e disciplinas aparentemente muito afastadas do "social" que lhe está subjacente. Por vezes, trata-se apenas de um conjunto de hipóteses que é necessário testar, validar através de novas observações e integrar em teorizações renovadas.

Em suma, inúmeras vezes procedemos a uma forma de teorização que tende a "naturalizar" o que pretendíamos considerar como um processo, se não intencional, pelo menos historicamente produtor de desigualdade e de injustiça. O que se toma como um equivalente do princípio rousseauista da perversão social da 
natureza humana, transformar-se-ia, deste modo, em perversão humana da natureza social, neste caso das relações homens/ mulheres.

Um bom exemplo desta assunção pode ser encontrado nas tentativas de explicação das diferenças de tamanho, de corpulência e de estatura, entre os homens e as mulheres, em termos de desigualdade social ou de desigualdade injusta de género, já que, deste modo, se corre o risco de esquecer que tais diferenças podem ser interpretadas como o produto de adaptações e construções sócio-históricas e culturais. A demonstração do enviesamento implícito ao argumento de que existe uma relação entre diferença natural entre homens e mulheres e desigualdade social de género, não pode, porém, ser linear, implicando necessariamente, como argumentaremos ao longo do artigo, mudanças de registo do raciocínio que é preciso desenvolver para obter este tipo de conclusão.

\section{Em torno de explicações "naturalistas" para a "desigualdade" entre sexos. Um exemplo problemático... a problematizar!}

Para poder falar-se de desigualdade é preciso dispor de um esquema explicativo, ou de uma teoria de referência, em função das quais a constatação dessa diferença possa aparecer como uma distorção do que deveria ser uma distribuição normal. É preciso, pois, dispor de uma norma, já estabelecida e aceite, ou, pelo menos, de um elemento de comparação valorizado e tendo estatuto de critério. Falar de desigualdade implica, assim, sempre a referência a "outra coisa" para além da constatação da diferença manifesta (Young, 2005; Théry, 2007).

A desigualdade (ou a igualdade), a partir do momento em que não se situa num registo matemático, não pode ser considerada como um simples julgamento de facto, objetivo, mas torna-se também um julgamento de valor, já que envolve, desde logo, opções normativas sobre uma dada visão do mundo. Encontramos a mesma ideia em Aristóteles, quando advoga que as disposições individuais, naturalmente desiguais, têm como consequência uma distribuição "proporcional" de bens, de poder, de honra, etc., produzindo o que atualmente se apelidam "desigualdades justas". Ou ainda, quando considera que uma ação injusta, isto é, uma ação que rompe o equilíbrio inicial, produz uma desigualdade inaceitável de posição, de situação ou de propriedade. O que, na ótica do filósofo citado, exigiria uma correção.

Em qualquer caso, na enunciação da desigualdade mobilizamos, ao mesmo tempo, uma teoria da justiça e uma explicação factual acompanhada de um juízo axiológico. A teoria da justiça é de elaboração teorética e especificada de forma precisa. A explicação factual, por seu turno, exige toda uma variedade de teorias, de crenças, de convicções do justo, que operam como normas ou referências destinadas à apreciação do fenómeno evidenciado.

Não existem, pois, desigualdades, a fortiori desigualdades sociais, sem esse conjunto de normas ou referências requeridas para a enunciação de um tal julgamento de valor. Dito de outro modo, a desigualdade (ou a igualdade) não se constata, aprecia-se e julga-se. Claro que, os registos nos quais se inscrevem estes 
pressupostos normativos podem variar, tanto na sua natureza, como na sua formulação, mas o julgamento de valor tende a perdurar como expressão do justo. $\mathrm{Ou}$ seja, tende a ser enunciado como a consequência lógica da apreciação feita, perdurando, mesmo quando parece não enunciar senão uma diferença na estatura física dos homens e das mulheres.

Para precisar o argumento iremos centrar-nos precisamente no exemplo da diferença de estatura entre homens e mulheres. Com efeito, um certo número de observações, ao longo da História, relativas à variação de estatura dos homens e das mulheres, foram agregadas sob a designação, de alguma forma lapidar, de "desigualdade homem/ mulher". A questão, "em que medida isto se constitui como uma desigualdade?" será, pois, o leitmotiv da reflexão na primeira parte do artigo.

\section{Um exemplo a problematizar: as diferenças de estatura entre homens} e mulheres

A partir de vários dados disponíveis ao longo do tempo, constatou-se que, em média, existe uma diferença significativa de estatura entre os homens e as mulheres (Kleiner, 2014; Touraille, 2008). A medida desta diferença varia sensivelmente segundo as fontes, mas situa-se sempre entre 10 a $15 \mathrm{~cm}$ de altura. Quanto ao tamanho propriamente dito dos homens e das mulheres, ele varia, com o tempo, em mais ou menos $10 \mathrm{~cm}$. Por outro lado, no mundo, e em particular no mundo ocidental, desde o fim do século XIX, o tamanho dos homens aumenta mais rápido que o das mulheres. Assim, no que diz respeito por exemplo à França, com a idade de 20 anos, a diferença entre os homens e as mulheres era de $9,7 \mathrm{~cm}$ em 1970, de $11 \mathrm{~cm}$ em 1980 e de $12,1 \mathrm{~cm}$ em 2001. No Norte da Europa, a diferença era, no mesmo período, superior $(14 \mathrm{~cm}$ ) e em Portugal inferior (cerca de $10 \mathrm{~cm}$ ) (Eurostat, 2000; De Saint Pol, 2006).

Acrescentemos dois elementos adicionais para compor o quadro analítico. Primo, as observações paleoantropológicas e históricas mostraram que, quando existe evolução do tamanho, é a estatura da mulher que começa a baixar, antes da do homem. E, logo que a estatura reaumenta, para ambos, o crescimento da mulher é mais tardio que o do homem. Secundo, todos os inquéritos de opinião contemporâneos, os estudos históricos comparativos, iconográficos, literários e outros, estabelecem que as mulheres preferem (dentro de determinados limites) os homens maiores (Bourdieu, 2002 [1998]; Herpin, 2006; Lovejoy, 1981; Touraille, 2008).

Que teorias explicativas e que conceção da justiça se encontram mobilizadas quando se afirma que a diferença de estatura entre os homens e as mulheres se constitui como uma "desigualdade"? Para já, deixemos de lado a teoria da justiça já que, neste caso, ela pode ser considerada como a simples afirmação de uma estrita igualdade entre homens e mulheres, ou, se preferirmos, a asserção de uma identidade humana universal presente tanto nos homens como nas mulheres. São as teorias explicativas possíveis e não triviais que devem reter a nossa atenção. Não triviais, no sentido em que todas aquelas que assentam apenas sobre a enunciação de um "preconceito sexista" traduzem somente este tipo de preconceito e não enunciam nada mais que o preconceito. $\mathrm{O}$ antecedente ("preconceito sexista") é, deste modo, retoricamente transmutado em consequente. 
Centremo-nos pois, para discussão do exemplo escolhido, nas teorias explicativas que podem ser invocadas e que derivam de registos científicos diversos. Esquematicamente, e na impossibilidade de considerar todos os quadros explicativos possíveis, três serão aqui referenciados: o genético, o evolucionista e o comportamental. Estes três domínios de explicação podem efetivamente aportar uma chave de compreensão possível das causas da diferença de estatura entre os homens e as mulheres. A diferença de estatura é então explicada (ou melhor, tem uma causa explicativa conhecida) à luz de uma dada perspetiva analítica. Deste modo, o julgamento de desigualdade não seria senão uma espécie de julgamento adicional, traduzindo a vontade daquele que o manifesta de ir para além da explicação causal. Um julgamento, que ultrapassaria a explicação proporcionada à luz da teoria, integrando-a numa apreciação normativa não contida na teoria explicativa mobilizada. Logo, renunciando ao julgamento de facto, logicamente produzido no seio da teoria, em proveito de um julgamento de valor, enunciado a partir de um outro registo, ele próprio sustentado por uma conceção de justiça cujos termos nem sempre são precisados. Percorramos pois os três domínios de explicação selecionados (genética, evolucionista e comportamental).

\section{O registo explicativo da genética}

Os geneticistas demonstraram que, em matéria de diferença de estatura física entre homens e mulheres, existem genes reguladores do crescimento e que estes operam diferencialmente segundo o sexo. Genes de alguma forma responsáveis pelas variações de fenótipos constatadas. Tais informações são relevantes e não podemos ignorar a sua contribuição na prossecução da nossa reflexão. Desde já, podemos perguntar-nos se não estaremos perante um imponderável da natureza, da nossa natureza animal, cujo mecanismo genético seria revelado. Em suma, como teria dito "Jacques, o fatalista", de Diderot, "tudo isto estava escrito". A desigualdade, neste caso, não seria nada mais do que uma constatação de diferença regular e explicável fenomenalmente graças ao contributo da ciência genética contemporânea (Lovejoy, 1981; Hall, 1982). Uma "desigualdade" em certa medida "lógica", ou seja, "esperada", intelectual ou psicologicamente, e confirmada empiricamente. Como o são as diferenças, constatadas, explicadas e admitidas por todos, por exemplo dos picos das montanhas, da altura das árvores, ou de muitas outras coisas observáveis. Notemos a este respeito que não falamos de "desigualdade" entre os picos das montanhas, ou entre as árvores. Constatamos o facto, explicamo-lo eventualmente, mas não fazemos qualquer julgamento de valor. Um tal julgamento não faria obviamente sentido, uma vez que consideramos a justiça somente em função das ações e das relações humanas. Não deveríamos, pois, retirar as mesmas conclusões no que diz respeito à diferença de estatura entre homens e mulheres? Não temos teoria da justiça a invocar no que diz respeito à natureza genética dos humanos. Constatamos o facto, explicamo-lo seguramente, mas não podemos retirar dele qualquer julgamento de valor em termos de justiça, já que não possuímos, também neste caso, uma ação humana propriamente dita. Ainda assim, detenhamo-nos um pouco mais nesta ideia. 
Se continuarmos com a explicação genética, verificamos que a mesma demonstra que a regulação do crescimento se realiza antes de mais com a finalidade, se assim podemos dizer, de proteger as funções vitais dos mamíferos que somos. Em caso de fome ou de malnutrição deixamos de crescer para proteger o cérebro, o coração e outros órgãos fundamentais. Uma espécie de repartição prioritária do investimento fisiológico. E claro que as mulheres, por exemplo para proteção dos fetos em gestação, vão experienciar esta forma de compensação mais cedo e talvez de forma mais drástica (Touraille, 2008).

Coloca-se aqui o acento numa diferença funcional ou, mais exatamente, num processo fisiológico de diferenciação. De forma global, afirmamos que, funcionalmente, os homens não são mulheres e vice-versa. Dito de outro modo, colocámos em evidência um princípio de discriminação que "constrói" o dimorfismo sexual ${ }^{1}$ admitido para a espécie humana ${ }^{2}$ (Alcock, 2001; Goodman e Leatherman, 1999; Hall, 1982; Lovejoy, 1981).

Mas, de que ponto de vista, sob que teoria da justiça, isto seria "injusto" e suscetível de constituir um facto de "desigualdade"? Dizendo-o de outro modo, poderemos nós, em nome de um valor social estatutário de igualdade homem/mulher, considerar que estes processos fisiológicos colocam esse valor em causa ao ponto de se gerar uma "desigualdade" verdadeiramente injusta entre homens e mulheres? Responder afirmativamente a esta última questão é envolver-se em todo o tipo de especulações, mais ou menos gratuitas, sobre a moral intrínseca do que chamamos, de forma pouco consistente, "a natureza".

Com efeito, considerando o que procuramos discutir, o problema é que segundo os próprios geneticistas tudo isto não explicaria senão uma parte bastante limitada (mais ou menos $5 \%$ ) da variação do tamanho entre os humanos. A genética revela-se pois impotente para explicar 95\% desta variação (Goodman e Leatherman, 1999). Em suma, para a nossa argumentação o mais importante continua por revelar. Para isso, consideremos um outro registo explicativo, no caso as teses evolucionistas, as quais talvez possam fornecer-nos boas razões para falar de desigualdade homens / mulheres, tratando-se da estatura de uns e de outros.

\section{O registo explicativo evolucionista}

De uma forma muito sintética, podemos salientar que, no caso dos mamíferos, entre os polígamos, constatamos uma diferença de tamanho entre macho e fêmea muito maior que entre os monogâmicos (Alexander, 1974). ${ }^{3}$ Entre os gibões que são

De forma estrita, não nos confrontamos com um "dimorfismo" que deixa sempre entender que os seus termos-objetos são exclusivos. Trata-se aqui de distribuições cruzadas da estatura dos homens e das mulheres. No melhor dos casos poderíamos falar de uma tendência para o dimorfismo dos sexos.

2 Claro que isto exclui todos os casos de indeterminação. Não que eles não representem outras categorias empíricas e não tenham sentido analítico, mas, num tal procedimento de diferenciação, não desempenham qualquer papel. São neutros ou, se preferirmos, neutralizados. Desde logo, a operação de discriminação dicotómica pode produzir todos os seus efeitos. 
monogâmicos impenitentes, há pouca diferença de tamanho entre macho e fêmea, ao contrário do que acontece com os chimpanzés, possuidores de grande vitalidade sexual e espírito astucioso. Dito de outro modo, sobretudo se a concorrência é forte, é preferível ser grande e potente, ou seja, possuir os mais imponentes meios de defesa (chifres, cornos, dentes, garras...) e, consequentemente, ter a capacidade de se reproduzir mais facilmente. O que é, para inúmeros etólogos evolucionistas, a intenção estratégica do comportamento sexual dos mamíferos e que, a longo termo, permite difundir na espécie os marcadores do tamanho grande.

Como reconhecemos trata-se da tese da seleção natural sexual. Não precisamos de a explorar já que é largamente conhecida, ainda que numerosas reservas existam sobre a otimização da fisiologia das mulheres neste domínio. Os paleoantropólogos concordam que a pelve feminina (Homo sapiens fêmea) é mais adequada para a bipedia do que para o parto. Alguns concluem mesmo que, para a espécie humana e por razões obstetricais, teria sido preferível que as mulheres grandes tivessem sido privilegiadas na evolução da espécie. O que não foi de facto o caso ${ }^{4}$ (Touraille, 2008). Também não exploraremos o facto de que as armas de defesa que os humanos provavelmente utilizaram para melhor crescer por via da reprodução foram menos os dentes, as garras, etc., e mais o cérebro. E isto complexificar-se-ia ainda mais se considerássemos que o cérebro pode ser concebido como uma ferramenta de adaptação voluntária, ferramenta essa ela própria adaptável (Damásio, 2011 [1984]).

Em suma, convocando explicações de tipo evolucionista, saímos do determinismo genético, ou, pelo menos de uma visão puramente determinista do genético, para, dando espaço ao comportamento adaptativo dos indivíduos, tornar este determinismo mais relativo - não tenhamos medo dos oximoros - ou seja, relativo a estes comportamentos, os quais envolvem verdadeiramente ações desenvolvidas pelos humanos (Alcock, 2001; Goodman e Leatherman, 1999). Nestas condições, temos nós a possibilidade de encontrar matéria para enunciar um julgamento em termos de "desigualdade" e/ou de "injustiça", tratando-se da diferença de tamanho entre os homens e as mulheres?

De forma alguma, porque, uma vez mais, não dispomos de uma teoria da evolução ${ }^{5} \mathrm{sob}$ o foco da qual teria sido possível declarar como injustas as ações ou efeitos dessas ações em termos de tamanho dos homens e das mulheres. Estamos ainda em tentativas de explicação do fenómeno, da constatação empírica, sem que este possa ser reportado a alguma coisa como um "dever ser", que funda sempre - como o

4 A este respeito Maurice Abitbol (em Touraille, 2008: 236) afirma, "não nos parece que a forma da bacia durante a evolução da espécie tenha sido orientada originalmente por referência a uma problemática obstétrica. A forma da pélvis durante a evolução hominiana e mais especificamente durante a evolução dos hominídeos foi mais orientada para a adaptação a um uso progressivo da postura eréctil, a locomoção bípede e o suporte das vísceras, do que pelo facto de resolver problemas obstétricos".

5 Ou de uma teoria alternativa à que foi elaborada no âmbito dos trabalhos de observação. Uma teoria, em suma, que estabeleceria a norma idealizada da evolução da espécie humana. O que já não se constitui, na verdade, como uma teoria científica, no sentido popperiano do termo, uma vez que não é falsificável. 
afirma Aristóteles - ojulgamento em termos de injustiça ou de desigualdade. É preciso, pois, ir além do registo evolucionista, em sentido estrito, e convocar, desta vez, uma explicação possível por via de comportamentos e de ações suscetíveis de serem apreciadas e julgadas em função de um critério de justiça. Por exemplo, um dos critérios que podemos encontrar e admitir como fundamental em Aristóteles. Este é geralmente o domínio da antropologia cultural, no seio da qual se ancoraram as abordagens em termos de "género".

\section{O registo explicativo comportamental}

Neste caso, são as práticas culturais, como normalmente as designamos, que podem ser invocadas, fornecendo possíveis argumentos probatórios para um equacionar da "desigualdade homem/mulher" em função de um princípio de justiça reconhecido. Dito isto, envolvemo-nos num terreno já largamente balizado, discutido e controverso no seio da paleoantropologia e da antropologia biológica (Alcock, 2001; Goodman e Leatherman, 1999). A incidência da cultura, ou seja, das formas de fazer, reenviando e incorporando um conjunto de crenças partilhadas, por exemplo tratando-se da distribuição de recursos alimentares, é largamente abordado por estas disciplinas, nomeadamente em termos de plasticidade fenotípica e singularmente de dimorfismo sexual de estatura. ${ }^{6}$

Destas práticas culturais reteremos pois, em primeiro lugar, as que, em muitos lugares e por longos anos, não permitiam às mulheres alimentar-se antes dos homens. Estes apropriando-se dos melhores pedaços não deixavam às mulheres senão uma porção reduzida de alimento, de qualquer forma a menos substancial. O que, ainda que não o possamos comprovar aqui mas raciocinando sobre o longo termo e falando globalmente, desencadeava efeitos fisiológicos sobre o crescimento e o tamanho das mulheres. Compreendemos então que nos períodos de recessão alimentar as mulheres sejam as primeiras a diminuir e as últimas a recuperar a estatura, logo que ultrapassado o período de "vacas magras" (Allen e Sachs, 2012; Atse e Adon, 2015; McLean, 2013).

Como constata Priscille Touraille (2008: 226), “o conceito de adaptação em condições de nutrição desfavoráveis é um dos que faz correr mais tinta na antropologia biológica. O paradigma culminou com a famosa hipótese do small but healthy (pequeno mas saudável) de David Sackler". Esta hipótese considerava que as mulheres de pequena estatura poderiam enfrentar mais facilmente a ausência de alimento, porque as suas necessidades calóricas eram mais reduzidas. Porém, como destaca Touraille (2008), para as mulheres, o que emerge como uma vantagem para a sobrevivência, torna-se uma desvantagem para o parto.

De qualquer modo, parece que desta vez podemos falar, pelo menos numa primeira aproximação, de desigualdade de tratamento entre homens e mulheres. ${ }^{7}$

6 Sem que seja sempre bem estabelecida a função que aí tem o genótipo. A plasticidade fenotípica será um simples efeito do ambiente no qual se exprime o genoma ou comporta adaptações genéticas? (Touraille, 2008). 
Isto, por referência a uma teoria da justiça, que é atualmente a nossa, a saber, e para dizê-lo rapidamente, a que se encontra subjacente à Declaração Universal dos Direitos do Homem (entenda-se claro dos humanos!) e que preconiza que nenhuma discriminação fundada sobre a categoria sexual de pertença (e mais precisamente de atribuição) possa operar na vida social lato sensu.

Aceitamos pois a ideia de que todo um sistema de justificação ou, para adotar a retórica de Boltanski e Thévenot (1991), uma teoria das justificações praticadas, prevalece a esta distribuição de recursos alimentares. E, como tal, solicita uma conceção de justiça suscetível de ser explicitada. A distribuição alimentar foi, na verdade, durante muito tempo concebida como uma distribuição proporcional às necessidades e méritos de uns e outros, ${ }^{8}$ representando, pois, a aplicação de um princípio de justiça promovido por Aristóteles e jamais negado: o princípio de justiça "distributiva".

O que mudou, e que nos permite enunciar atualmente um julgamento de desigualdade, é a finalidade teleológica deste sistema de justificação. Quais são os valores pelos quais fazemos apelo a este sistema? O bem comum da polis, como teria dito certamente Aristóteles, o respeito por uma tradição fundada sobre a ideia de uma natureza diferente dos homens e das mulheres (Gilligan, 1982), uma ontologia diferencial como a apelidámos inúmeras vezes, ou até mesmo outras representações da ordem das coisas. Dito de outro modo, as justificações utilizadas no passado, e portanto o "procedimento justo" que as acompanhava, não pode produzir atualmente senão efeitos "desiguais" por referência às justificações que hoje utilizamos. Em suma, o nosso julgamento de desigualdade a respeito da estatura dos homens e das mulheres seria um julgamento-sanção. Um julgamento que avalia os efeitos históricos da prossecução de determinadas finalidades que transgridem os fins que atualmente adoptamos. Um tal julgamento tem tendência, para formularmos rapidamente o argumento, a fazer da Justiça, nomeadamente sob a forma de Direito instituído, o fim a perseguir. O valor de Justiça é assim não somente um valor cardinal da conceção que preconizamos do "viver conjunto", mas também, um valor que enquadramos sob os auspícios da igualdade e da equidade, o que John Rawls (1971) apelida Justice as Fairness. Ou, se preferirmos, a fazer da Justiça, o Bem a prosseguir. E é aqui que nos separamos de Aristóteles. ${ }^{9}$

Evidencia-se, pois, que para enunciar um julgamento de desigualdade quanto às práticas culturais ancestrais fundadas sobre uma distribuição discriminatória dos recursos alimentares, é preciso renunciar à ideia de que possa

7 Como destacam Allen e Sachs, a alimentação “encerra as mulheres na sua subordinação” (2012:36).

8 Por exemplo, sob o pressuposto, socialmente admitido e legitimado, de que cabia ao homem assegurar a defesa e a sobrevivência física da família, nomeadamente por via do trabalho e, nos primórdios, por via da caça.

9 Ainda que John Rawls tenha procurado atenuar esta divergência, admite que existem de facto duas conceções da justiça em função das representações do bem. Opõem-se assim as conceções pluralistas do bem e as conceções unitárias do bem. As primeiras relevam do liberalismo político e encontram a sua fonte na Reforma e nas suas consequências filosóficas. As segundas decorrem da tradição teleológica cristã e têm a sua origem na filosofia grega platoniana e aristotélica (Rawls, 1993: 237-241). 
existir um Bem superior que venha justificar esta discriminação e admitir que a igualdade de tratamento dos homens e das mulheres permite ipso facto a concretização da justiça.

Resta-nos pronunciarmo-nos sobre se este julgamento retrospetivo de comportamento "desigual" e "injusto" pode suportar uma teorização teleológica, quer procedendo como um "processo sem sujeito", quer aceitando, num grau muitas vezes mal definido, a intencionalidade da ação. Por outras palavras, será que este julgamento de desigualdade poderá entrar numa lógica de justificação, revelando, no facto constatado e agora possivelmente explicado, os efeitos perversos de uma ancestral, ou mesmo trans-histórica, dominação masculina?

A questão, aqui, não é a de reabrir o debate, já em si muito intenso, sobre os factos da dominação. A questão é a de saber se podemos passar de um julgamento factual sobre a desigual distribuição de estatura entre homens e mulheres para um julgamento de valor sobre a injustiça de tratamento das mulheres, tendo em conta o nosso atual sistema de justificação.

A resposta pode ser positiva, mas sob condições epistemológicas precisas, a saber: (1) não abandonar o terreno da refutação possível em prol da revelação ex-post; (2) comprovar a intencionalidade real dos atores sociais implicados. ${ }^{10}$

\section{Dos julgamentos de facto aos julgamentos de valor: questões críticas epistemológicas}

A argumentação segundo a qual existiria, em última instância, sob os factos bem estabelecidos nos registos da genética, do evolucionismo e da antropologia cultural, uma lógica escondida, no caso, a da dominação, deve ser afastada. Não porque o fenómeno de dominação não tenha lugar, mas porque não podemos inferi-lo dos factos retidos sem lhe atribuir o papel de uma hipótese aditiva dotada de uma potência de realização de algum modo metafísica, como teria dito August Comte. Dito de outro modo, é porque se opera um salto argumentativo e cognitivo, passando de uma lógica causal atual a uma lógica intencional virtual, que deverá ser afastado este tipo de raciocínio.

Sobre este assunto a sociologia da dominação, numa perspetiva bourdieusiana, esclarece-nos utilmente. A própria lógica da dominação não é funcionalmente operativa senão quando é partilhada pelo conjunto dos "protagonistas". Bourdieu (2002 [1998]) sublinhou bem a ideia de que em matéria de dominação, e de dominação masculina em particular, a valorização diferenciada de sexos sob a forma de género deve ser partilhada pelos dois. Não afirmamos pois, desde logo, que uma "injustiça" é feita às mulheres no que diz respeito à sua estatura mais reduzida se o que pode conduzir a isso é partilhado pelos dois "protagonistas". O que é efetivamente o caso quando os

10 Esta parece ser também a perspetiva do paleontólogo Jean-Paul Demoule (2017), ao referir, na sua última obra, que a diferenciação social no Neolítico é marcada pela distinção nítida entre os chefes e os demais. Neste contexto, assiste-se a uma construção sociocultural intencional da imagem da mulher como claramente subordinada. 
dados revelam que as mulheres preferem aliar-se a homens maiores que elas (Bourdieu, 2002 [1998]; Herpin, 2006), e reciprocamente, como podemos razoavelmente inferir, quando os homens preferem aliar-se a mulheres mais pequenas que eles. Por outras palavras, as diferenças de estatura são culturalmente procuradas pelos homens e pelas mulheres (Touraille, 2008). Como destacou no seu tempo La Boétie (2016 [1548]) isto significa dizer que a "servidão" é voluntária, porque resulta da mesma capacidade para perseguir o que cada um entende ser o seu "Bem" e porque é o produto do mesmo esforço para perseverar no seu Ser, como teria dito Spinoza. Este conatus social significa que uma mesma "competência" 11 habita os homens e as mulheres e, portanto, que é o jogo, a combinatória destas competências que produz, como efeito emergente, os fenómenos de dominação. Aqui, não há teoria da justiça (ou da injustiça) a apresentar a título explicativo. Ela continua externa e não pode ter senão o sentido de uma reinterpretação, de uma releitura à luz dos seus próprios fins; o sentido de uma explicação/justificação teleológica ou metafísica.

Pensar que a diferença de estatura reconhecida obedece fundamentalmente a uma lógica escondida, talvez mesmo inconsciente para os indivíduos implicados, é fazer desta diferença a simples manifestação fenomenal desta lógica, o simples fenómeno de uma entidade dissimulada, mas atuante. De uma entidade retrospetivamente percebida e decifrada somente pelo filtro da sua pressuposição. Como se uma espécie de "mão invisível" da dominação masculina estivesse em marcha desde sempre, sem que fosse necessário imputá-la a uns ou a outros. E tudo isto porque no registo das preferências ideológicas contemporâneas a igualdade estrita dos homens e das mulheres se afirma como o ideal de justiça a concretizar.

Deste modo, realiza-se um "salto" explicativo que não poderia fundar-se, nem na teoria da justiça em referência à qual é enunciado o julgamento de desigualdade, nem na cadeia de razões explicativas que foram mobilizadas precedentemente. Esta cadeia permite-nos provavelmente compreender como se desenrolou o processo de produção da diferença de estatura, de atribuir talvez um peso decisivo aos comportamentos culturais dos humanos e de apreciar, por referência à nossa conceção da justiça - que reclama o tratamento igualitário dos humanos -, o resultado historicamente produzido por tais comportamentos. Mas, epistemologicamente falando, nada nos permite ir para além desta constatação e atribuir um sentido intencional ou uma finalidade teleológica (qualquer que seja o nível) a este fenómeno de diferença de estatura. Ao fazê-lo estaríamos a criar um fenómeno ex-nihilo presumido in fine operar como princípio causal.

A única possibilidade reside na mudança de quadro epistemológico e na passagem do que poderia ser tomado como uma explicação, relevando de uma teoria local (a incidência fenotipal, e até possivelmente genotipal, das práticas culturais), para uma compreensão, fazendo apelo a uma conjetura relativa ao sentido escondido do fenómeno e interpretável em termos de desigualdade e de injustiça feita às

11 Por "competência" queremos significar todas as formas refletidas, relativas ao real ou ao imaginário, que participam dos sistemas de justificação considerados. Isto enquadra tanto o consciente como o inconsciente, tanto o saber como a crença, tanto o dito como o silenciado, tanto o contingente como o simbólico, etc., logo, o que apelidamos racionalidade humana. 
mulheres. Por outras palavras, se passarmos de um raciocínio dedutivo - baseado sobre o que nos pode fornecer a experimentação e a teoria genética tornando possível a causalidade cultural - para um raciocínio indutivo, propondo uma causalidade primeira, pelo menos antecedente e teleologicamente orientada, cujo sentido seria atribuído por referência à teoria da justiça à qual aderimos.

Deste ponto de vista, podemos identificar aqui um duplo equívoco. Desde logo, quanto à natureza do raciocínio e ao tipo de "verdade" que autoriza. Em segundo lugar, quanto à pertinência ou à validade intrínseca das entidades explicativas mobilizadas. $\mathrm{O}$ primeiro equívoco remete para os debates clássicos que atravessaram a filosofia do conhecimento e que, dos gregos ao Círculo de Viena, procuraram estabelecer os fundamentos do conhecimento verdadeiro. Este, para dizê-lo da forma mais esquemática possível, é interno ou externo ao processo de conhecimento? A verdade está subordinada ao processo de conhecimento ou acontece o contrário? O que significa que não majoramos a interpretação epistémica, subsumindo a hipótese testável (a incidência genética da causalidade cultural), sob uma conjetura ad hoc, uma crença, ainda que razoável (por exemplo, o sentido ou o progresso da história, as estruturas antropológicas da humanidade, a sexuação do mundo, etc.). Mudamos, pois, de registo discursivo e de regime de administração da prova. Em suma, não se trata de estabelecer a probabilidade de sucesso da hipótese (sempre compreendida entre $0 \mathrm{e} 1$ ); procuramos somente confirmar a validade da hipótese ad hoc, ou seja, a tender para a probabilidade de 1. Dito de outro modo, a tender para uma "tautologia", como afirmava Popper (1973 [1959]). Este rejeitava na verdade as explicações fora do campo da lógica científica inscrevendo-as no pensamento dogmático. O primeiro é falsificável, o segundo, não. ${ }^{12}$ E é aqui que reside o segundo equívoco.

Com efeito, no primeiro caso subordinamos a explicação à verificação empírica da ligação entre práticas culturais, diferenciando homens e mulheres, e a variação fenotipal e/ou genotipal de estatura, com uma probabilidade incerta (logo a calcular) e cuja interpretação epistémica se faria, como vimos, em termos de vantagem ou de desvantagem relativa (vantagem para a sobrevivência, desvantagem para o parto). No segundo caso, subsumimos o fator desvantagem para o parto sob o conceito universal de dimorfismo sexual e interpretamo-lo em termos de desigualdade ou de injustiça feita às mulheres, tendo em conta a nossa conceção da justiça ancorada numa ideia de igualdade estrita. Neste último caso, a verificação empírica é supérflua já que é uma redundância do conceito de dimorfismo sexual. O enunciado torna-se, desta forma, universalmente verdadeiro e depende somente da nossa conceção da justiça.

Estamos pois perante dois tipos de enunciado cujo valor lógico ou epistémico não releva do mesmo regime de verdade. ${ }^{13}$ Um é uma conjetura refutável, o outro,

12 Para Popper (1973 [1959]), o grau de probabilidade lógica de um enunciado varia na razão inversa do seu conteúdo empírico; quanto mais aumenta mais tende para a tautologia e menos é útil para a descoberta científica.

13 Não desenvolveremos aqui os fundamentos lógicos da distinção, que interseta, em boa medida, o objeto da célebre controvérsia entre Carnap e Popper (ver Popper, 1999). 
uma conjetura irrefutável - se quisermos utilizar a terminologia de Popper. O que quer dizer, se podemos exprimir-nos deste modo, que a intenção demonstrativa não tem o mesmo fim num e noutro caso. Para o primeiro, trata-se de estabelecer o que poderíamos apelidar como um "facto de observação", do qual apenas se pode dizer que deixa entender que existe uma certa plasticidade do genoma; para o segundo, trata-se de fundar, sob um argumento singular (entre todos os argumentos singulares possíveis), um julgamento de valor estritamente dependente da apreciação subjetivamente afirmada e relativa à conceção de justiça. E pois a componente ou o lugar da subjetividade que distribui os registos de enunciação e os níveis discursivos. Daí a oscilação epistemológica que enunciámos.

É também somente sob esta condição de viragem epistemológica que o julgamento de "desigualdade homens/mulheres", relativo à diferença de estatura, pode receber o seu sentido pleno de "desigualdade" de tratamento e de "injustiça social" (sempre no sentido da nossa conceção contemporânea de justiça). É pois claro que nenhuma argumentação explicativa de tipo causal, assente em registos de saber relativamente bem constituídos (biologia genética, etologia humana, antropologia cultural ou outros), poderia fundamentar um qualquer julgamento em termos de "desigualdade homem/mulher" no sentido do princípio de justiça de igualdade contido na conceção contemporânea do "justo". Para enunciar um tal julgamento, é preciso abandonar a lógica explicativa causal e admitir uma explicação que faça apelo, qualquer que seja a modalidade, a uma forma de intenção, de desenho, de fim, que constituiria a razão última dos factos constatados - no nosso exemplo as diferenças de tamanho. Uma espécie de julgamento pelas causas finais.

Ora, epistemologicamente falando, este tipo de raciocínio teleológico, estas explicações pelas "causas finais", não podem constituir-se como demonstrações, mas somente como interpretações hipotéticas - no sentido em que convocam uma hipótese ad hoc -, muitas vezes frágeis, exigindo, em qualquer caso, um exame mais detalhado. Nomeadamente, porque a lógica do raciocínio tende para a tautologia; porque os "saltos analíticos" são eventualmente realizados no seguimento das linhas explicativas; porque cedemos à introdução de argumentos finalistas, etc.

Foi o que procurámos mostrar através do nosso exemplo, que nos permitiu afirmar que o diferencial de estatura entre homens e mulheres poderia ser enunciado em termos de "desigualdade homem/mulher" e, como tal, de "injustiça" se, e somente se, nos colocarmos fora do campo das explicações admitidas e praticadas nas diversas disciplinas às quais fizemos apelo, tanto no campo das ciências biológicas, como no das ciências sociais e humanas. O que implica que um tal julgamento é, sobretudo, um julgamento de valor e não um julgamento de facto - uma enunciação factual - que só é possível com a condição de aderir a um esquema explicativo, mobilizando uma teoria preestabelecida (aqui, a justiça como igualdade estrita, o "justo" derivando do direito que formaliza esta conceção). Logo, que um tal julgamento releva de uma teoria admitida e não de uma teoria construída, empiricamente fundada e testada.

Claro que tudo isto não impede de fazer da discriminação de tratamento das mulheres, ao longo da história das nossas sociedades, uma questão de filosofia política aplicada, se pudermos definir-lhe a finalidade. A questão foi, e continua a ser, 
explicitamente colocada pelos movimentos feministas em virtude de um princípio de justiça fundado sobre a igualdade dos humanos e plasmado na Declaração Universal dos Direitos do Homem. No entanto, a questão que aqui se coloca é ética e política e não epistemológica.

\section{Considerações finais}

Resulta de tudo isto que o julgamento de desigualdade, quando nos situamos numa démarche explicativa das ciências humanas e sociais, deve ser utilizado com uma grande precaução. A fragilidade semântica da noção favorece, não duvidemos, usos pouco rigorosos, forçados e por vezes claramente incorretos. Temos tendência, com efeito, a passar, retornando ao nosso exemplo da diferença de estatura - empiricamente constatada, aritmeticamente transcrita, disciplinarmente explicada - para a afirmação da "desigualdade social homens/mulheres" e para a ideia de injustiça que esta conota semanticamente. Mas, como argumentámos ao longo do artigo, isto seria logicamente abusivo, já que mudamos de registo explicativo: abandonaríamos, para dizê-lo rapidamente, o regime da prova empírica (o das ciências experimentais que faz apelo a teorias "locais"), pelo regime interpretativo (o do sentido, do significado que atribuímos aos factos e que reclama uma teoria "geral" ou teleológica). É este salto epistemológico que não podemos efetuar.

Ojulgamento de desigualdade exige que, pelo menos, seja precisada, mais do que geralmente fazemos, a teoria da justiça que lhe serve de suporte. E aqui se encontra certamente, para as ciências sociais, o desafio teórico contemporâneo para a compreensão do que é enunciado quando nos referimos a desigualdades sociais e à injustiça que elas podem comportar.

É inegável que a reflexão deve ser conduzida de novas maneiras para definir um pouco melhor o que Aristóteles conceptualizou em termos de relação entre o "Bem" e o "Justo". Pode, ou deve, haver uma "prioridade" de um sobre o outro? E, qual a consequência quando os confundimos, quando fazemos do "Justo" um "Bem"? Os debates atuais, nomeadamente norte-americanos, já balizaram as respostas possíveis, salientando que uma mudança de paradigma da justiça já aconteceu em múltiplos domínios da vida social. O "Justo" tornou-se o valor cardinal do "Bem". O "Justo" não como "justeza" - ajustamento à situação, ao ambiente, ao contexto - mas o "Justo" como aplicação do princípio de justiça como equidade e, muitas vezes, como igualdade ou identidade. Por outras palavras, o "Justo" não é mais um resultado pragmático da ação, mas um princípio constitutivo do político.

John Rawls (1971), nos debates suscitados pela sua Theory of Justice e a sua conceção de rightness as fairness, proclamará a prioridade do "Justo" e o "bem da justiça" como um princípio constitucional da sociedade política. ${ }^{14} \mathrm{Na}$ Europa, este debate foi prosseguido com os trabalhos, entre muitos outros, de Sylvie Mesure e 
Alain Renaut (1999). Estes vêm sublinhar que as divergências, as diferenças, as distribuições sociologicamente constatáveis, ou seja, empiricamente descritas e mensuráveis, não podem ser qualificadas como "injustiças sociais" senão por via de uma definição explícita do justo e do seu valor no seio de uma teoria da justiça. Dito de outro modo, epistemologicamente falando, procedemos a uma espécie de hiperbolização do raciocínio, a algo como um equivalente da démarche de Descartes em busca da certeza nas suas Méditations Métaphysiques.

Ora, como havia enunciado Paul Ricoeur a propósito da noção de falta, "a partir de um acidente, uma descrição eidética não é mais possível, mas somente uma descrição empírica" (1950: 27). O que nos incita a não utilizar a noção de injustiça social a não ser com extrema prudência metodológica. Em todo o caso, para o sociólogo, coloca-se a exigência de distinguir sempre a descrição e a explicação causal empírica, da qualificação dos fenómenos ou atribuição predicativa em termos de justiça. Não o fazer é abandonar o terreno da abordagem compreensiva da sociologia - logo, o papel que aí desempenham as "ideias", as "crenças", os "valores", como diria Weber - e substituí-lo pelo das tomadas de posição ideológicas, as quais têm tendência a reduzir as constatações empíricas a evidências simples, evacuando toda a reflexão.

Em suma, associamo-nos, neste âmbito, à posição weberiana sobre a questão dos valores, tanto no plano da démarche metodológica do sociólogo, como na interpretação a atribuir ao que Weber (1965 [1922]) apelidou o "sentido objetivo". ${ }^{15} \mathrm{Ou}$ seja, o sistema normativo ideal-tipo pelo qual se reconstrói o sentido subjetivo prosseguido pelos atores sociais concretos.

Para concluir e retornar ao nosso exemplo. O sociólogo pode aceitar sem dificuldade as proposições e raciocínios que foram assumidos nos diferentes registos que aqui foram considerados. Na condição, no entanto, de continuar atento aos debates e controvérsias suscitadas pelas interpretações às quais eles conduzem. Por exemplo, quando é considerado que os comportamentos culturais têm uma incidência sobre o genótipo que, de alguma forma, sancionaria a desigualdade de tratamento das mulheres ao longo da história (Touraille, 2011). Ficando atento a tais controvérsias o sociólogo mantém-se no quadro das explicações causais refutá veis. ${ }^{16} \mathrm{~A}$ diferença de estatura entre os homens e mulheres só é interpretável como "injustiça" sob a condição de sair deste quadro e de se referir a um sistema de valores no qual a igualdade estrita é considerada como a realização do "justo". Ora, sobre este ponto, o sociólogo não poderia assumir esta proposição senão na condição de poder estabelecer que a vontade de rejeitar este ideal de justiça é a motivação real de comportamentos culturais que conduziram à diferença fenotipal e mesmo genotipal. Para dizê-lo em termos weberianos, que o sentido objetivo, reconstruído

15 O texto central nesta matéria é o seu "Ensaio sobre a neutralidade axiológica", de 1913. Para uma discussão do "sentido objetivo" em Weber, ver Jean-Marc Tétaz (2004).

16 Por exemplo, poderíamos enfatizar que nos nossos países desenvolvidos já há muitas décadas que a maioria dos homens e das mulheres partilham os mesmos alimentos, recebem os mesmos cuidados, redistribuem os seus papéis sociais, etc. O que não impede que se mantenham sempre entre 10 e $15 \mathrm{~cm}$, em média, de diferença de estatura entre os dois sexos. 
pelo sociólogo, é o que proporciona a maior coerência à variedade de sentidos subjetivos evidenciados pelos indivíduos concretos. O que, no nosso caso, supõe que uma intencionalidade presidiu à ação discriminatória multipolar e trans-histórica, cujos efeitos se registam nos poucos centímetros que separam os homens e as mulheres. Ora, esta intencionalidade nada tem de princípio an-hipotético, à maneira platónica, isto é, o que justifica todas as hipóteses subjacentes, acima consideradas. Esta intencionalidade parece mais uma hipóstase ficcional, do que um princípio postulado para a defesa de uma causa. Em todo o caso, ela não pode assumir um sentido objetivo no sentido weberiano, pela simples razão de que deve ser, por definição, teleologicamente orientada. Toda a intenção o é de alguma coisa.

Em suma, a diferença de estatura não pode ser sociologicamente reconhecida como uma "desigualdade social", logo uma injustiça feita às mulheres, a não ser que apele a um princípio de efetuação simplesmente hipostasiado.

\section{Referências bibliográficas}

Alcock, John (2001), The Triumph of Sociobiology, Oxford, Oxford University Press.

Alexander, Richard (1974), Darwinism and Human Affairs, Seattle, University of Washington Press.

Allen Patricia, e Carolyn Sachs (2011), "Women and food chains: the gendered politics of food", em Psyche Williams-Forson e Carole Counihan (orgs.), Taking Food Public. Redefining Foodways in a Changing World, Nova Iorque, Routledge, pp. 23-40.

Aristóteles (1984), Ética a Nicômaco, São Paulo, Victor Civita.

Atse, Achi Amédée-Pierre, e Kouadio Patrick Adon (2015), “Laisse-moi manger ta viande: le partage des protéines chez les Akyé", Journal des Anthropologues, 140-141, pp. 193-212.

Boltanski, Luc, e Laurent Thévenot (1991), De la Justification. Les Economies de la Grandeur, Paris, Gallimard.

Bourdieu, Pierre (2002 [1998]), A Dominação Masculina, Rio de Janeiro, Bertrand Brasil.

Damásio, Antonio (2011 [1984]), O Erro de Descartes. Emoção, Razão e Cérebro Humano, Lisboa, Circulo de Leitores (edição revista e aumentada).

Demoule, Jean-Paul (2017), Les Dix Millénaires Oubliés Qui Ont Fait l'Histoire, Paris, Fayard.

De Saint Pol, Thibaut (2006), "Corps et appartenance sociale: la corpulence en Europe", Données Sociales 2006. La Société Française, Paris, INSEE, pp. 649-656.

Eurostat (2000), Panel Européen des Ménages, Bruxelas, Comissão Europeia.

Eveleth, Phyllis (1975), "Differences between ethnic groups in sex dimorphism of adult height", Annals of Human Biology, 2, pp. 35-39.

Gilligan, Carol (1882), In a Different Voice. Psychological Theory and Women's Development, Cambrige, MA, Harvard University Press.

Goodman, Alan H., e Thomas L. Leatherman (1998), “Traversing the chasm between biology and culture: an introduction", em Alan H. Goodman e Thomas L. Leatherman (orgs.), Building a New Biocultural Synthesis. Political-Economic perspectives on Human Biology, Ann Arbor, University of Michigan Press, pp. 3-41.

Hall, Roberta (1982), Sexual Dimorphism in Homo sapiens. A Question of Size, Nova Iorque, Praeger. 
Herpin, Nicolas. (2006), Le Pouvoir des Grands. De l'Influence de la Taille des Hommes sur Leur Statut Social, Paris, La Découverte.

Kleiner, Véronique (2014), “Pourquoi les femmes sont-elles plus petites que les hommes?", Film Documentaire, Paris, co-produção ARTE France-Point du Jour, PICTA Production, CNRS Images-CNDP (1 $1^{\text {a }}$ difusão).

La Boétie, Etienne de (2016 [1548]), Discurso sobre a Servidão Voluntária, Lisboa, Antígona. Lovejoy, C. Owen (1981), “The origin of men”, Science, 211, pp. 341-350.

McLean, Alice (2013), "The intersection of gender and food studies", em Ken Albala (org.), Routledge International Handbook of Food Studies, Nova Iorque, Routledge.

Mesure, Sylvie, e Alain Renaut (1999), Alter Ego. Les Paradoxes de l'Identité Démocratique, Paris, Edições Aubier, col. Alto.

Popper, Karl Raimund (1973 [1959]), La Logique de la Découverte Scientifique, Paris, Payot.

Popper, Karl Raimund (1999), Les Deux Problèmes Fondamentaux de la Théorie de la Connaissance, Paris, Hermann Editeurs.

Rawls, John (1971), A Theory of Justice, Cambridge, MA, The Belknap Press of Harvard University Press.

Rawls, John (1993), Justice et Démocratie, Paris, Seuil.

Ricoeur, Paul (1950), Philosophie de la Volonté. Le Volontaire et l'Involontaire, Paris, Aubier.

Tétaz, Jean-Marc (2004), “'Sens objectif': la fondation de l'interprétation du sens de l'agir social dans une théorie philosophique du sens", Archives de Sciences Sociales des Religions, 127, pp. 167-197.

Théry, Irène (2007), La Distinction de Sexe. Une Nouvelle Approche de l'Egalité, Paris, Odile Jacob.

Touraille, Priscille (2008), Hommes Grands, Femmes Petites. Une Evolution Coûteuse. Les Régimes de Genre comme Force Sélective de l'Evolution Biologique, Paris, Editions de la Maison des Sciences de l'Homme.

Touraille, Priscille (2011), "L'indistinction sexe et genre, ou l'erreur constructiviste", Critique, 1 (764-765), pp. 87-99.

Weber, Max (1965 [1922]), Essais sur la Théorie de la Science (1904-1917), Paris, Plon.

Young, Iris Marion (2005), On Female Body Experience. "Throwing like a Girl" and Other Essays, Nova Iorque, Oxford University Press.

Michel Messu. Professeur honoraire, Université Paris Descartes, Centre de Recherche PHILèPOL, Philosophie, Épistémologie et Politique, Paris, França. E-mail: michel.messu@wanadoo.fr

Cristina Albuquerque. Professora auxiliar na Universidade de Coimbra, Coimbra, Portugal. E-mail: crisalbuquerque@fpce.uc.pt

Receção: 29 de dezembro de 2017 Avaliação: 10 de janeiro de 2018 